\title{
A Study on the Construction of College-Enterprise Collaborative "Production-Teaching-Entrepreneurship" Practice Base of Business English Major in the "Belt and Road" Context
}

\author{
Liu Haiyan \\ Chengdu Polytechnic, Hi-tech Zone, Chengdu, China \\ 21047288@qq.com
}

Keywords: Production-teaching-entrepreneurship, Co-cultivation, Practice base

\begin{abstract}
This article firstly introduces the demands and requirements for business English professionals in the context of the "Belt and Road" Initiative, analyzes the industrial environment in Chengdu and the lack of existing practical training practice in talent cultivation, points out the importance of innovation and entrepreneurship education in the training of professionals. Then it provides suggestions for the construction of college-enterprise collaborative "production-teaching-entrepreneurship" practice base: finding suitable business partners; developing the specialty collaboratively; combing innovation with entrepreneurship and facilitating entrepreneurial incubation; implementing college-local government cooperation and connecting vocational talents training of different levels; serving the society and influencing relevant sectors.

\section{“一带一路”背景下商务英语专业 “产学创” 校企协同育人实践基地建设研究 \\ 刘海燕 \\ 成都职业技术学院，高新区，成都，中国 21047288@qq.com}

关键词：产学创; 协同育人; 实践基地

中文摘要. 本文首先介绍 “一带一路” 背景下对商务英语专业人才的需求和要求, 分析成都 地区的跨境电商产业环境，剖析人才培养现存的实践环节缺失问题，指出专业人才培养中创 新创业教育的重要性。针对 “产学创” 校企协同育人实践基地的建设给出建议：寻找合适的 企业伙伴; 开展专业共建; 双创贯通, 创业孵化; 校地合作, 中高职人才培养衔接; 服务社 会，辐射影响。

1. 引言

“一带一路” 内涵是 “五通三同”。“五通” 就是政策沟通、设施联通、贸易畅通、资 金融通、民心相通。“三同” 就是利益共同体、命运共同体和责任共同体。现阶段的重点是 基础设施建设，基础设施建设完成，物流打通后，将连接沿线国家的贸易往来。随着我国与 “一带一路” 沿线各国的经济政治联系和文化交流日益加深，实施这一倡议所产生的当代中 国经济产业升级、产业转型必然带来迫切的人才需求。四川处于陆上丝绸之路和海上丝绸之 路的交汇点，是连接西南西北、沟通中亚南亚东南亚的重要交通走廊，内陆开放的前沿阵地 和西部大开发的战略依托, 是 “一带一路” 有机衔接的重要门户。解决 “一带一路” 进程中的 人才短缺，是未来教育界契合国家倡议的重大课题，也是当前高校商务英语专业必须承担的 
责任 ${ }^{[1]}$ 。跨境电商被称为互联网时代的 “网上丝绸之路” ，在经济全球化、贸易一体化的快 速发展的背景下，跨境电商凭借着电子化、全球化、简介化等优势在国际贸易中成为重要的 商业模式 ${ }^{[2]}$ 。学校人才培养要服务于产业, 服务于经济, 商务英语专业的人才培养模式也应 做相应的调整, 从过去更多强调语言能力的培养调整到突出专业实操技能, 适应 “一带一路” 发展需求的跨境电商人才。

\section{2. 商务英语专业 “产学创” 校企协同育人实践基地建设的必要性}

\section{1 成都跨境电商产业环境}

2016年1月国务院正式下发《关于同意在天津等12个城市设立跨境电子商务综合试验区的 批复》, 成都成功入选。成都市政府专门成立了跨境电商公共服务平台, 为跨境电商企业提 供线上一站式服务, 集合海关、检验检疫、外汇管理局等行政部门, 办理业务一站直通, 高 效便捷。平台还具备一站式通关, 一键式平台、店铺、商品管理功能, 同时为个人消费者提 供身份证信息认证、订单跟踪等服务。该平台预期打造跨境电商产业链综合服务体系。此外, 成都市政府也在积极的引进跨境电商项目入驻自贸试验区。成都市政府相关部门也出台相应 的激励政策和文件，推进跨境电商产业的发展。2017年8月11日，成都市商务委、成都市财政 局对外发布了《关于申报成都市2017年跨境电子商务支持资金的通知》，并公布了《成都市 2017年度跨境电子商务支持资金实施细则》 (以下称《细则》)。《细则》中提出安排专项资 金用于打造成都市的跨境电子商务产业、提高跨境电子商务发展水平、完善跨境电子商务支 撑和服务体系 ${ }^{[3]}$ 。

综上, 无论是从国家大环境, 还是成都市地方政策来看, 对于商务英语专业的学生都会 是很好的机会, 关键在于专业的人才培养能否满足目前乃至以后的成都经济发展。

\section{2 商务英语专业人才培养现状}

在对商务英语专业往届248名毕业生的问卷调查中, 就 “你认为商务英语专业毕业生在以 下哪些方面的能力与企业的要求存在较大差距? ”一题的回答, 其中, 125 人, 占调查人数 $50.4 \%$ 的毕业生选择了 “实践动手能力”。171人, $68.95 \%$ 的毕业生认为专业学生需要在实践环节加 强。实践动手能力是商务英语专业毕业生的软肋。专业人才培养需找准方向, 大力推进学生 实践操作能力培养, 开拓路径, 寻求专业实训实践机会。

\section{3 创新创业教育是教育部强调的重点, 也是学校发展的重心}

教育部教职成2018（1）号文 “教育部等六部门关于印发《职业学校校企合作促进办法》 的通知” 中明确指出 “产教融合、校企合作是职业教育的基本办学模式，是办好职业教育的 关键所在” ，要 “发挥企业在实施职业教育中的重要办学主体作用，推动形成产教融合、校 企合作、工学结合、知行合一的共同育人机制, 建设知识型、技能型、创新型劳动者大军, 完善现代职业教育制度”。文件从校企合作形式、促进措施以及监督检查等多方面促进、规 范和保障职业学校校企合作 ${ }^{[4]}$ 。该 《办法》的颁布, 将更加有利于商务英语专业与企业校企 合作项目的开展，提升专业学生实训实践能力。

教育部教职成2015（6）号文《教育部关于深化职业教育教学改革全面提高人才培养质量 的若干意见》中对创新创业的教育提到了前所未有的高度, 其中包括以下重要指导性意见: 以增强学生就业创业能力为核心、面向全体学生开设创新创业教育专门课程群、推动校企共 建校内外创业教育实践平台、切实增强职业院校技术技能积累能力和学生就业创业能力。可 见，创业教育已成为高职院校各个专业人才培养体系中十分关键的一个环节。

成都职业技术学院目前正处于四川省优质高职院校建设周期。优质院校建设期间，学院 将坚持 “创新驱动、重点突破、内涵发展、特色发展” 的建设原则, 按照 “需求导向、产教 融合、双创贯通、内涵提升” 总体思路, 突出产教融合协同育人和创新创业教育，建成国内 
一流、国际可比的优质高职院校, 引领服务成都现代服务业发展。商务英语专业在校企合作 的过程中也需要充分融入创新创业教育, 顺应学院建设发展需要, 也是对教育部相关政策的 积极响应。

\section{3. “产学创” 校企协同育人实践基地建设内容}

综上多方面分析，寻求跨境电商类企业共建 “产学创” 校企协同育人实践基地将会是商 务英语专业人才创新、创业实践能力培养的有效途径。

\section{1 寻求合适的企业合作伙伴}

校企合作不能流于形式，随便找个企业签个协议、挂个牌就算完成。需要多方面考核, 考核企业的本身实力、经营范围、经营状况、企业文化和企业愿景等。有些企业本身实力虽 然足够支撑这个校企合作项目, 却不愿意涉足职业教育领域; 也有企业与高校合作意愿强烈, 但是本身处于发展期或初创期，心有余而力不足。也有企业校企合作经验不足，前期信心满 满, 往后的合作中拖沓推诿, 后劲不足, 没办法长期持续合作。

经过前期的多次考察与沟通，商务英语专业锁定四川安德在线网络科技有限公司为意向 合作伙伴，共同打造专业 “产学创” 校企协同育人实训基地。公司以供应链和电子商务系统 为基础, 以仓储, 物流为中心, 整合成六大业务板块, 即跨境电子商务分销平台、国际国内 电子商务分销平台、第三方软件、国际物流、国内物流和国内仓储。公司精益于 $\mathrm{B} 2 \mathrm{~B} 、 \mathrm{~B} 2 \mathrm{C}$ 等领域为客户提供专业的、个性化的第三方仓储、物流、配送和信息金融服务; 效力于为广 大跨境电商提供国际小包、国际专线、国际快递等具有综合优势的物流服务。公司经营范围 契合专业人才培养方向, 公司也是崇州市电商协会副会长单位, 拥有行业背景; 更重要的是 公司在校企合作方面已有近10年的历史, 积累了很多校企合作经验, 拥有广东理工学院跨境 电商实训中心、成都大学跨境电商实训基地等成功案例。

\section{2 校企专业共建}

校企双方商议无异议，签署校企合作协议，进入项目实质性建设阶段。首先要成立专业 共建委员会。委员会成员由学校、企业和跨境电商行业共同组成。专业共建委员会负责专业 建设的指导、管理和监督工作, 专业建设团队负责具体的建设任务实施。借助企业资源, 采 用问卷、现场访谈、实地考察等方式开展专业调研, 完成专业人才需求报告, 据此进行专业 人才培养方案的调整, 课程设置更新。将商务英语专业人才培养重心从先前的 “英语+商务” 调整到 “英语+商务+跨境电商实操”，使人才培养更具针对性，就业更有指向性。

\section{3 线上线下实训平台打造}

在互联网+时代，实训条件的打造也需线上线下双管齐下。线上可以链接成熟的跨境电商 平台速卖通、亚马逊和WISH等, 同时拥有由合作企业开发的跨境电商ERP模拟系统, 可以完 成订单管理、产品刊登、包装验货、称重出库等跨境电商全流程模拟操作。

线下实训中心按照功能布局分为: 教学实操区、选品商议区、摄影设计区、创业孵化区、 产品展示区、宣传留影区、物流售后区。学生在进行ERP模拟操作后, 进入真实作业区, 完 成跨境电商各流程业务操作。

\section{4 双创贯通, 创业睬化}

结合成都商品特色, 组建专业跨境电商创业团队。专业学生通过自主报名加选拔的方式 成立创业团队。创业项目有两种形式, 一是创业团队在学校老师和企业导师的双重指导下完 成选品、店铺搭建、店铺运营等工作; 二是企业直接将承接的社会项目交由学生团队来完成, 学生团队成为企业的项目组之一, 完成跨境电商某一环节的任务, 比如: 图片处理、产品描 述、英语客服等工作。两种形式都需要企业的资源, 技术指导、项目提供等。除了成立创业 
团队, 还可以举办专业创新创业大赛, 企业提供经费赞助, 学生团队根据自身的条件和想法, 开展各式创业活动。让学生动起来, 在行动过程中积累经验, 锻炼能力, 通过创业实践, 提 升创业能力。专业和企业将联合对表现突出的创业团队进行辅导, 提供便利条件和支持, 助 力创业孵化。

\section{5 校地合作, 中高职人才培养衔接}

企业落户崇州市，享受崇州市政府大力的优惠政策和扶持力度。企业有足够号召力召集 崇州市中职学校与我院共同成立跨境电商职教集团, 由我院商务英语专业完成对当地中职学 校商务英语类专业的专业指导, 开展师资培养, 实训资源共享等。通过举办中高职创新创业 大赛, 加强中高职学生、老师之间的交流, 加深中职学校学生对学院商务英语的了解, 对于 商务英语专业来讲也是一个选拔优秀中职学生的途径。通过单独招生政策, 为优秀中职学生 提供一个学历提升和继续学习的机会。

\section{6 服务社会, 辐射影响}

成都良好的跨境电商氛围意味着大量的跨境电商人才需求。与企业合作成立跨境电商人 才培训中心，面向社会提供跨境电商培训项目。培训不仅仅解决培训学员会操作的问题，培 训方还将整合行业资源, 聚集有跨境电商人才需求的企业, 搭建跨境电商人才就业平台, 为 参加培训的人员提供就业机会，同时也为跨境电商企业提供人力资源。

\section{4. 结束语}

校企合作应该是三赢的，企业、学校和学生都能从合作中受益，实践基地的建设需要同 时具备生产、教学和创业三大功能。企业在合作项目中的精力和时间投入是需要有回报和收 益的, 只有企业能在合作中受益, 这样的合作形式才能够长久。当然, 在企业受益的同时, 学生也在参与创业项目的过程中, 锻炼了实操能力, 解决专业以往人才培养中的一大短板, 人才培养质量得以提升。在和企业的合作过程中, 专业团队的老师也能有机会参与企业真实 的项目, 提升实践教学能力。此外, 企业的专家也将作为校外师资资源, 成为专业教学资源 的有益补充。希望在教育部等六部委校企合作新政的促进下, 商务英语专业与四川安德在线 网络科技有限公司的合作能够开花结果，成果丰硕。

\section{致谢}

本文为四川省教育厅 2017 人文社科类重点项目：“一带一路” 视阈下高职商务英语专业 人才培养研究（课题编号：17SA0030）的研究成果之一。

\section{References}

[1] Liu Haiyan, the Cultivation of Business English Majors in Sichuan Higher Vocational Colleges in "Belt and Road" Initiative Context, Labor and Social Security, vol.389, pp. 20-21, 2017.

[2] Yuan Jiazhou, Fang Ling, the Status and Countermeasures of Cross-border E-Commerce in Suzhou under the Background of "Belt and Road" Initiative, Market Weekly, vol.7, pp. 84-86, 2017.

[3] http://www.cdwl.gov.cn/index.php?m=content\&c=index\&a=show\&catid=15\&id=6277.

[4] http://www.moe.gov.cn/srcsite/A07/s7055/201802/t20180214_327467.html. 